\title{
LA ESTÉTICA DE LA DISOLUCIÓN Y LA INFINIVERSIÓN EN LA POESÍA DE J. Á. VALENTE
}

\author{
THE AESTHETICS OF THE DISSOLUTION \\ AND THE INFINIVERSIÓN IN THE POETRY OF J. Á. VALENTE
}

\section{Sandra Lucía DÍAZ GAMBOA}

\author{
Investigadora \\ sandralucia05@yahoo.es
}

Resumen: A partir de la obra poética de José Ángel Valente construimos una estética de la disolución en la que todo parece disolverse en su propio interior y esta infiniversión crea una red que liga las problemáticas del infinito, el ritmo, la materia, la forma y el vacío.

Abstract: From the poetic works of José Ángel Valente we construct an aesthetic of dissintegration where all seems to dissolve in itself, and this infiniversión, thus creating a net which binds the problems of the infinite, rhythm, matter, form and emptiness.

Palabras clave: José Ángel Valente. Disolución. Infiniversión. Trascendencia. Trasparencia. Retracción.

Key Words: José Ángel Valente. Dissolution. Infiniversión. Transcendence. Transparency. Retract. 


\section{PARA SITUARNOS}

La infiniversión ${ }^{1}$ que opera en la poesía de J. Á. Valente, en la que lo informe, la vacuidad, la unicidad y lo ambiguo disuelven la palabra en silencio, crea una estética de la disolución que se sumerge en la plenitud de lo desconocido, en un tránsito anterior al mundo y a las palabras. Silencio que nos borra sin fin. De este modo, en un ensayo de la Piedra y el centro, titulado «Meditación del vacío en Xemaá-el-Fna», contemplamos el pasaje de la infiniversión y destrucción:

[...] y puede todo quedar de súbito borrado. La plaza es, repentinamente, la multitud y su vacío: la desaparición de todos, de todo y del que mira [...]

El sol de la tarde en su descenso va deshaciendo las figuras y las borra. Luego, borra sus sombras. Fna-el-fna: primero, la desaparición o la extinción; después, la extinción de la extinción. Con toda la multitud dentro, no visible, quedan sólo la plaza y su vacío.

[...] «Signos de mensaje incierto: infinitas posibilidades de juego a partir del espacio vacío», dices, cuando ya la voz — a punto de extinguirse- y la plaza y la página en blanco son una sola y misma cosa. Filtrada luz oscura, unificado pájaro del aire, plaza: plaza de los extintos y los muertos [...] (Valente, 2008: 283).

Meditación de las formas, creación del vacío: tránsito, transparencia, unicidad, reflejo; fluctuación entre adentro y afuera. La forma es el vacío. La plaza es puro aire, pura luz, cóncava de sueños. El vacío es potencialidad, contiene el secreto de las metamorfosis, por ello Xemaá-el-Fna es un modelo de relaciones fluidas; un flujo donde la efusión es una difusión. Estamos ante un álgebra sonora de un sistema abierto:

Di = difusión, disolución, disipación, desintegración.

La plaza, Xemaá-el-Fna, comprende la isotopía de lo cóncavo, vive en la inminencia de los bordes, ceñidos a un espacio en donde la acumulación, la inmersión, las adherencias, las declinaciones, lo conexo son términos topológicos y posiciones que se evaporan. La plaza, densa o conexa, se agrieta localmente o deshace, y va hasta el final de su propia difusión y se expande. Finalmente, va al fondo del desvanecimiento.

El vacío como sustancia lo penetra todo, tiene un carácter dinámico, que tiende al mismo tiempo hacia la transformación continua y hacia la

${ }^{1}$ Concepto que tiene que ver con una propiedad de propiedades, interioridad, vacuidad, frontera de lo indecidible, oscilación entre el cero y el infinito, etc. El desarrollo de este concepto se encuentra en Díaz G. (2008: 123-130). 
unidad originaria. El vacío implica, también, el alumbramiento, por esta razón, para Valente, el poema no se escribe, se alumbra; y por ello es inútil corregirlo ya que el vacío no se puede acrecentar.

El subfondo semántico, originado por el símbolo del vacío, hace que se interrelacionen conceptos y palabras, creando familias léxicas y campos conceptuales del lenguaje que convierten en metonimias vocablos que inicialmente no lo parecen, e incluso poemas enteros. El intertexto se transforma entonces en otro nombre del nombre en proceso: una metonimia pura. Se revela así el fondo metonímico del lenguaje y por ello la «corrección» no afecta nunca a la esencia del fundamento. Es una variación suya inagotable, otro modelo de lo pleno, de su carácter transfusivo y traslativo, como señala Laozi: «la gran plenitud es como vacía; entonces es inagotable»².

Este aspecto inagotable permite a las palabras sobrepasarse y acceder a una especie de resonancia allende las resonancias, donde el vacío parece desplegar el más allá del poema. P. Ryckmans subraya: «Puesto que lo esencial es indecible, el poema sólo puede hablar rodeando el tema, circundando un vacío» (1993: 142).

De forma recursiva, los intervalos del poema permiten que éste sugiera la existencia indecible de un más allá del poema. El vacío comunica la melodía del silencio. Desplaza los límites: «Progresión continua hacia un horizonte que se nos revela inalcanzable para llevarnos siempre hacia él» (Valente en Chillida, 1998: 109). Infinito abierto que, en lógica, se relaciona con el famoso teorema de Incompletitud de Gödel ${ }^{3}$.

La palabra poética, el sonido dotado de sentido, el callar y la pausa, constituyen según Bajtín (1981: 126) «una estructura unitaria e ininterrumpida, una totalidad abierta (incompletable)», tal como lo escuchamos en el poema de Valente «(Canción del eterno inretorno)» de Cántigas de Alén:

$$
\begin{aligned}
& \text { [...] pájaro que en la infinitud del aire vuela, } \\
& \text { en el vacío del aire, } \\
& \text { hacia el horizonte que jamás se alcanza } \\
& \text { y nunca ya poder - quedarme así- } \\
& \text { regresar al origen para siempre borrado (1996: 92). }
\end{aligned}
$$

\footnotetext{
${ }^{2}$ En la tradición estética oriental, el vacío, según Francois Cheng, es, «a la vez estado supremo del origen y elemento central en el mecanismo del mundo de las cosas» (1993: 47).

${ }^{3}$ Este Teorema propone que «Toda formulación axiomática de teoría de los números incluye proposiciones indecidibles» (Hofstadter, 1987: 19). En la demostración de este Teorema se oculta un bucle extraño, está trabada con la escritura de una proposición matemática auto-referencial.
} 
La estética de la disolución en la poesía de Valente está relacionada, también, con la impermanencia, una cualidad que es característica de la estéticaascética del sabi-wabi ${ }^{4}$, que se basa en la experiencia de la desposesión y la disponibilidad.

El poema retiene su realidad, resulta wabi, ya que éste significa «ser verdadero para sí mismo» (Suzuki, 2005: 192), en cuanto indica y manifiesta su autenticidad propia, «indiferente a las circunstancias» (2005: 192) y por esta extraña fuerza puede producir en quien lo lee efectos de satorí, es decir, que en su corto florecer se contiene el universo y, en su aparente inmovilidad, se puede leer la tensión entre el surgimiento y la desaparición, tensión que sería característica de una estética de la disolución y, que lo es, de la pintura Zen, infiniversión de los límites en cuanto devenir y descomposición de lo creado, tal como la describe Herrigel:

El que sabe «leer» verdaderamente esta escritura percibe, más allá de la paz y la inmovilidad aparentes, la tensión aguda entre el devenir y la descomposición, entre el surgimiento y la caída, entre la aparición y la desaparición; siente cómo se estremece la criatura en el transcurso de la creación y la desintegración, criatura fugitiva pero absoluta (1999: 51).

El arte oriental capta la vida de las sombras, su progresión. Se trata de la misma soledad en que vive la poesía de Valente, en la que vibra el adentro de las cosas y, así podemos escuchar la música del qué, del adónde del nunca y del cuándo del adónde de la nada, como en el poema titulado «Nubes para Antonio Saura»:

Por un instante viven

las formas.

Arden.

Se disuelven en sí.

Son nada.

La nada

en la que el mundo es súbita

fulguración

de memorias borradas (2006: 840-841).

${ }^{4}$ Para profundizar sobre la estética del Sabi-Wabi vid. Suzuki (2005: 26-27, 29, 171, 174, 190-194, 213-214, 217). 
En los textos de Valente reconocemos la triple o cuádruple simultaneidad interior de un simbolismo formal, funcional y conceptual que determina la fluctuación del objeto que va desde su disolución hasta su síntesis abstracta (Díaz G., 2009: 62-63).

Así como en la estética de esta poesía predomina la disolución de las formas y las oscilaciones entre las apariciones y las desapariciones, también en el sufismo reconocemos esta dinámica oscilatoria y la vivencia de la evanescencia, fana. La última significación de la experiencia sufí, según Ibn Arabi, es la disolución o fana:

El mundo de las formas se recrea en cada instante para disolverse en el instante que sigue, aunque no lo percibimos en nosotros ni en el mundo que nos rodea, a causa de la infinita sucesión de imágenes de disolución y perpetuación (Ibn Arabi, citado en Benlabbah, 2008: 136).

La disolución, pasividad, pasión, pasado y paso, son experiencias en que se conforma el carácter fragmentario de la estética de la disolución; el paso es borradura, «extenuación del sujeto». Y esta aniquilación está en la base de la relación entre escritura y pasividad ${ }^{5}$.

Sombra de nadie, deshacimiento que predomina en la estética de la disolución, en la cual el aire del poema se desmorona desde el aire solo, el poema queda en suspenso, entra en disolución; su inminencia apunta hacia el polvo; la plenitud de su forma sólo consiste en indicar lo informe y en desaparecer en ese acto de significación. El canto es de aniquilación y reintegración total en la transparencia, incluido el lector que es colapsado y absorbido; así escuchamos su luz desértica en «Transparencia de la memoria»:

Como en un gran salón desierto al cabo los espejos

han absorbido todas las figuras, tal en el centro inmóvil bebe

la luz desnuda todo lo visible (2006: 365).

La ironía es la figura que mejor representa la estética de la disolución porque la aniquilación del mundo se opera precisamente por medio de la

${ }^{5}$ La escisión del yo se manifiesta en la fragmentación del texto. Blanchot amplía la interpretación de este fenómeno de los límites como sigue: «Hay relación entre escritura y pasividad porque la una y la otra suponen la borradura, la extenuación del sujeto: suponen un cambio de tiempo: suponen que entre ser y no ser algo que no se cumple sin embargo sucede como si hubiese ocurrido desde siempre [...] la ruptura silenciosa de lo fragmentario» (1990: 20). 
ironía. El movimiento en que la palabra poética se distancia y mira al mundo indirectamente, reflejado, como en el mito de Perseo. La escritura se libera de la petrificación de la realidad mirando las cosas de forma indirecta, tal como sucede, según Bajtín, en la escucha de la alteridad como función del «callar»:

El callar es el lugar de la Alteridad, de la plurivocidad, de la Plurilogía, del Diálogo, del Escuchar como espacio interpersonal [...]. El callar no ha salido del lenguaje. Sino que es también hablar indirecto, palabra distanciada, palabra irónica, parodia, sonrisa (Ponzio, 1995: 38-39).

La ironía subyacente en la estética de la disolución hace que el objeto, al mismo tiempo que se aleja de nosotros, adquiera un valor contextual, se reúna en el espacio con otros objetos que interesan para definirlo, como sucede en la teoría matemática de categorías $^{6}$ y en la máxima pragmática peirceana. La ironía hace que el ser partícipe del no ser, el objeto se determine a través de todos los objetos que no son él y tracen su contorno (Terceridad en Peirce ${ }^{7}$ ); sus límites dicen sí y no entre «la perfección de lo infinito»y «la negatividad de lo indefinido» ${ }^{8}$.

La ironía conjuga un movimiento de infiniversión en el que el cero se invierte en infinito. La ironía está implicada en el carácter inestable del mundo.

En la estética de la disolución, el espacio del poema es un espacio inestable, infinivertido ${ }^{9}$, en donde todo se vierte y declina:

TARDE final. Declina pálida la luz. Yo fluyo desde la herida abierta en mi costado hacia el endurecido río de tus venas (1999b: 278).

${ }^{6}$ Durante los años 1950-60 se crea la teoría algebraica de las categorías, en la que aparecen implicadas «clases de objetos que se caracterizan por un grado elevado de abstracción y de extensión» (Zellini, 1991: 159).

${ }^{7}$ La ironía está inmersa topológicamente en un continuo, que siempre vincula un tercer signo o conjuga las fronteras de los signos: «La terceridad viene a representar la ley general que rige el sentimiento (primeridad) y la acción (segundidad), otorgándoles continuidad» (Gorlée, 1992: 18).

${ }^{8}$ La ironía aparece como una fractura del discurso compacto, «el pensamiento aprende a mirar a derecha e izquierda», dice W. Jankelevitch, de este modo «si existe un objeto, existe una diversidad de objetos; o viceversa, si sólo existe un objeto, no existe objeto alguno. Así como en el El Sofista de Platón el ser participa del no ser [...] En cierto sentido, bastan dos coordenadas para situarlo: su relación con la conciencia que lo refleja, y su conexión virtual con otros cuerpos entre los cuales se recorta. Pero como el objeto nunca está solo, insensiblemente tendrá que compartir algo con todos los demás. Tal es, en efecto, la anfibología del límite: dice al mismo tiempo sí y no, afirma la sustancia en sus fronteras» (Jankelevitch, 1986: 22).

${ }^{9}$ El desarrollo de este concepto se encuentra en Díaz (2008: 123-130). 
El carácter infinivertido del poema tiene que ver con el problema del orden por fluctuación que combina caos y nacimiento, es el espacio del torbellino en cuanto «pre-ordenación de las cosas, su naturaleza en el sentido de nacimiento» (Serres, 1994: 51), y precipitación o aniquilación.

La obra poética de José Ángel Valente puede ser vista como una física naciente, de la que podemos desprender fácilmente el modelo Lucreciano. El carácter infinivertido de las palabras, los ritmos y las estructuras de los poemas nos hablan de todas las componentes de una hidráulica de la transparencia. Todo aquí, como en la física de Lucrecio, fluye, se vierte sin fin. Las palabras son porosas como los cuerpos y la naturaleza inestable se mueve por torbellinos. Del caos nace el orden y de la caída la libertad:

CAER en vertical. Sueño sin fin de la caída.

Qué repentina formación el ala (2000: 12).

Este breve verso de Valente resume la noción de Clinamen de Lucrecio, según la cual la desviación espontánea en el desplazamiento de los átomos permite compaginar las tesis atomistas con la defensa de la libertad.

La realidad es una materia compuesta por átomos que se desplazan y combinan en el vacío, que caen, pero tienen la capacidad de desviarse espontáneamente de la dirección vertical y de ese modo forman combinaciones no previsibles con otros cuerpos. Gracias a este elemento de espontaneidad de los átomos Lucrecio negó el carácter determinista del Universo e introdujo un elemento de libertad:

Vamos a ver, si los movimientos son solidarios, si siempre un nuevo movimiento nace de uno más antiguo siguiendo un orden inflexible, si por su declinación los átomos no tomarán la iniciativa de un movimiento que rompe las leyes del destino, ¿de dónde viene esta libertad concedida a todo lo que respira sobre la tierra...? (2003: 186).

El clinamen es el ángulo mínimo, el umbral que está más allá del tiempo, a partir del cual aparece el nacimiento o la muerte. El modelo Lucreciano trabaja con elementos mínimos ${ }^{10}$, infinivertidos, que definen umbrales y operan con residuos: el átomo que es pura circulación, el vacío que es puro depósito y la declinación vector puro.

\footnotetext{
${ }^{10}$ El vacío como estado cero de la materia, el átomo y el clinamen como estados mínimos.
} 
El modelo de Valente es homólogo del lucreciano, trabaja con despojos y humo de las ruinas: «El tiempo arrasa cada vez la vida. / El tiempo incendia cada vez la vida. / No vuelvas pues, no vuelvas con tu imagen,...» ${ }^{11}$. También en la física de Lucrecio todo fluye, se desprende y se arroja. Así lo describe el poeta:

[...] de cuantas cosas vemos es forzoso que sin parar fluyan y se lancen cuerpos que golpean los ojos y activan la vista; [... y no cesan de manar sones diversos por los aires... hasta tal punto desde toda cosa cada cosa en corriente se desprende y mueve hacia todas partes en torno, sin que en su discurrir tercie freno ni descanso, pues sin parar sentimos y siempre podemos ver, oler todas las cosas y oír que suenan (2003: 434-435).

Escucha infinita. Los poemas de Valente funcionan al modo lucreciano, con las texturas inestables de la materia del agua y el fuego:

\section{Baja}

tumultuoso el río

opaco de las sombras.

Piedras. Norte. Estalla

lejos la luz, muy lejos.

Andemos todavía (2000: 26).

Son versos y poemas infinivertidos en que las palabras son arrojadas en todas las direcciones como piedras, como sombras. Tal como sucede en la poesía de los metafísicos ingleses, especialmente en John Donne, poeta muy próximo en la lectura de Valente:

Cuántas veces he dicho vida y cuántas

tal vez muerte escondía sin saberlo,

cuántas habré cegado la esperanza,

cuántas, creyendo luz, habré arrojado

palabras, piedras, sombra, noche y noche

hacia el sol que tanto amo ${ }^{12}$.

${ }^{11}$ Valente, «Para una imagen rota» (1999: 452).

${ }^{12}$ Donne, citado en Jiménez (1998: 371). 
Las letras son consideradas por Lucrecio como átomos en continuo movimiento, que con sus continuas permutaciones creaban las palabras y los sonidos más diversos ${ }^{13}$.

Lucrecio anticipa una visión atómica del arte combinatorio, intuyendo en las estructuras conceptuales y en ciertas unidades básicas como módulos mínimos de integración elemental, los primordios, contextos semánticos y fónicos correspondientes a los reinos mineral, vegetal y animal ${ }^{14}$.

Las letras, como los átomos, son valoradas por sus posiciones, combinaciones y permutaciones; asimismo, considera los movimientos de las palabras en el verso, sus intervalos, entresijos y distancias:

[...] a menudo importa muchísimo a cuáles y en qué posición se pegan unos mismos primordios, y qué movimientos recíprocos provocan o reciben, y que es que mediante la leve trasformación de unos en otros unos mismos producen fuego y madera. Es lo mismo que sucede con las propias palabras «lumbre» $y$ «cumbre», que con una leve permuta de letras las marcamos con sonidos diferentes (2003: 160).

La intertextualidad que podemos encontrar entre las teorías de Lucrecio y el carácter infinivertido de la estética de la disolución en la poesía de Valente nos permiten mostrar cómo de un poema de éste cabe deducir todo el corpus lucreciano.

El poema seleccionado, «(Luces hacia el poniente)», pertenece a la variante textual del arquetipo del otoño, cuya recurrencia funciona como estructura límite de la periodicidad crucial de la existencia:

\section{Al lento sol que baja hacia la tarde ceder, abandonarse.}

\footnotetext{
${ }^{13}$ Lucrecio indica el valor de las posiciones: «Y mucho importa a menudo a cuáles y en qué posición, siendo los mismos, se pegan esos primordios, y qué movimientos recíprocos provocan o reciben, pues unos mismos constituyen el cielo, el mar, tierras, ríos, el sol, unos mismos las mieses, arbustos, animales, aunque se van moviendo y mezclando entre sí de diverso modo. Y digo más: acá y allá en nuestros propios versos ves muchas letras comunes a muchas palabras, a pesar de que te ves forzado a reconocer que versos y palabras difieren tanto en el significado como en la pronunciación de su sonido: tanto pueden las letras con sólo que cambie su ordenación. Ahora bien, los que vienen a ser los primordios de las cosas pueden proporcionar más combinaciones para de ahí producir acaso cada uno de los diferentes seres» (Lucrecio, 2003: 157).

${ }^{14}$ Por eso vio en ello Domínguez Rey «una cosmopoética singular» que alcanza a Mallarmé, al Modernismo y parte de la vanguardia, así como «una función ontológica y operativa entre lenguaje y actividad de la naturaleza» (2008: 36).
} 


\section{Declinación.}

El flujo del vivir

se ha ido deteniendo imperceptible

como el borde del vuelo o la caricia.

Aún dura leve lo que fuera huella

de su tacto tenue.

No sé si salgo o si retorno.

¿Adónde?

El fin es el comienzo.

\section{Nadie}

me dice adiós. Nadie me espera.

Entrar ahora en el poniente,

ser absorbido en luz.

con vocación de sombra.

$Y$ tú, que me has amado, sacrifica

a las divinidades de la noche

lo más puro de mí

que en tu secreto reino sobreviva (2000: 27).

Este poema, como casi todos los de Valente, contiene los componentes necesarios para ser considerado como modelo de la Física de Lucrecio:

- Es una física porque es una génesis de las cosas.

- Tiene el corpus de la física: caos, declinación, torbellinos, intervalos. $\mathrm{Al}$ caos lucreciano le siguen los intervalos. Al combate tempestuoso de los átomos, confusión caótica en un espacio vacío, sin límites, atravesado por movimientos, choques, vías y pesos distribuidos al azar sin conjunción, diseminados, opuestos, disjuntos; le siguen, no obstante, las traslaciones, las rotaciones, las vibraciones aleatorias, los lugares de detención en los puntos de colisión, los equilibrios momentáneos, los intervalos: se ha ido deteniendo imperceptible / como el borde del vuelo o la caricia.

- Génesis del texto. Las letras como átomos circulan y fluyen. Y la música del poema procede del ruido de fondo, del caos, de lo abierto: $A L$ lento sol que baja hacia la tarde / ceder, abandonarse.

- Génesis de la forma. Se escucha la forma, el esquema rítmico sobre el trasfondo del ruido que se vierte, se escucha la raíz ácuea: 
El flujo del vivir/ se ha ido deteniendo imperceptible /como el borde del vuelo o la caricia.

- Las distancias inexpresables están actualmente dadas. Las palabras son espaciales. Campo vectorial de flechas que indican el sentido. Semiótica topológica: Al lento sol que baja hacia la tarde...

- Las palabras son infinivertidas, viajan como átomos, mediante choques, encuentros múltiples e intervalos. Las travesías se enrarecen:

\section{Nadie}

me dice adiós. Nadie me espera.

Entrar ahora en el poniente,

ser absorbido en luz

con vocación de sombra.

- Atomismo, ritmo, fluxión, fluctuación e infiniversión. El lenguaje es disuelto en la abolición infinita de las formas.

- Universalidad, el torbellino en la corriente. La palabra es arrasada como torbellino en la naturaleza turbulenta.

- Presencia de seres vivos que son equilibrio y desequilibrio, flujo y torbellino.

- Estados fundamentales de la materia, átomos y vacío. Y extrapolación del tacto hacia los estados-límites de los cuerpos residuales. Fluidez, abandono del equilibrio, formación de turbulencias.

- Esta poesía, como la física de Lucrecio, se encuentra en las cercanías del nacimiento y de la muerte. Está en la naturaleza, en la abertura, en el nacimiento, en el milagro, en la falla.

- La espiral comienza en lo infinitamente pequeño de la declinación. Desmaterializacion de la materia.

- Infiniversión, turbulencia infinitesimal.

- La infiniversión asegura la transición del caos al orden u órdenes. En palabras de Serres:

La física intenta explicar cómo las cosas y el mundo se forman naturalmente a partir del caos atómico, es decir, cómo uno o varios órdenes pueden emerger del desorden, siendo la turbulencia lo que asegura la transición de uno a otro, lo cual parece contradictorio (1994: 47). 
- Los átomos nacen del tratamiento de los elementos curvos ${ }^{15}$. La figura del poema surge de la elipsis de la infiniversión, el eco o la sombra se convierten en germen.

- Pulverización que es polimorfismo, en que cada cosa tiene su propio tiempo:

Aún dura leve lo que fuera huella

de su tacto tenue.

- Modelo físico: constelación fluctuante de elementos innumerables móviles en todas las direcciones.

- Comprensión de la naturaleza en estado naciente. De la desviación puede nacer todo: Declinación. / El flujo del vivir

- Caída y ritmo. Caudales y vías.

- Ritmo: reversibilidad en la irreversibilidad.

- Infiniversión. Corriente y contracorriente: el fin es el comienzo.

- Tendencia mística de invertir lo firme en lo fluido. Inmersión: Entrar ahora en el poniente, / ser absorbido en luz / con vocación de sombra.

- Todo fluye, fluctúa, flota, ondula, ondea. Los objetos son fuentes. Olas y flujos de voces que vuelven en el viento. El espacio está lleno de ondas:

ceder, abandonarse

como el borde del vuelo o la caricia

...

No sé si salgo o si retorno

$$
\text { ¿Adónde? }
$$

- La desviación, el clinamen, perturba la caída vertical y permite los encuentros, el nacimiento, la diseminación y la muerte; libera los encadenamientos de causa y efecto:

${ }^{15}$ La curva implica la tangente, «no hay curvatura sin ángulo mínimo; así pues no hay atomismo sin declinación» (Serres, 1994: 29). 
Al lento sol que baja hacia la tarde

ceder, abandonarse.

Declinación.

El flujo del vivir

se ha ido deteniendo imperceptible

como el borde del vuelo o la caricia (2000: 27).

El texto declina, sigue la ley de la creación. Este poema posfigura la teoría física de Lucrecio:

[...] cuando los cuerpos se arrastran por el vacío en derechura hacia abajo a causa de sus propios pesos, en un momento indeterminado por lo general y en un lugar indeterminado empujan un poco fuera de su sitio, lo suficiente para poder afirmar que su movimiento ha cambiado. $Y$ es que si no tuvieran por costumbre desviarse, todas las cosas hacia abajo como gotas de lluvia irían cayendo a través del hondo vacío, y no surgirían encuentros ni se producirían golpes entre los principios: de esta manera la naturaleza no produciría nada nunca (2003: 185).

Todos los elementos que hemos reconocido en el poema de Valente como propicios para el surgimiento de una física lucreciana son una parte importante de los elementos que conforman un ritmo infinivertido, el cual, sin embargo, presenta un grado mayor de complejidad.

Aquí tenemos que hacer una matización significativa. Los torbellinos del ritmo infinivertido del poema son torbellinos inmóviles que configuran una estética de la disolución que está determinada por la interioridad.

La velocidad central de la infiniversión - ritmo que crece hacia adentro- en la escritura poética, aparece como incandescente torbellino inmóvil, que coincide con la encarnación de la palabra ${ }^{16}$.

El ritmo de la infiniversión es el mismo que se observa en la danza giróvaga. El derviche comienza a dar vueltas, con la cabeza ligeramente ladeada hacia la derecha y la energía de la trascendencia divina entra por su mano derecha extendida, atraviesa el canal de su cuerpo, para descender, pasando por la mano izquierda, hasta la tierra. En el escorzo físico del danzante, que gira de derecha a izquierda, abrazando a Dios y a toda la creación, el espíritu y la materia se unifican. Dice Juan Goytisolo que la ronda vertiginosa del sama

${ }^{16}$ Escribe Valente: «MOMENTOS privilegiados en los que sobre la escritura desciende en verdad la palabra y se hace cuerpo, materia de la encarnación. Incandescente torbellino inmóvil en la velocidad del centro y centro mismo de la quietud» (1999b: 119). 
de los derviches de Konya suscita el recuerdo del poder efímero de la escritura cuando inesperadamente accede a la gracia y alcanza la «levedad esencial», la plenitud creadora:

Los derviches giran como peonzas, sus túnicas forman anillos saturnales, el blanco torbellino de los pliegues deviene levitación [...] se incorporan a una u otra de las órbitas planetarias, [...] evolucionan con la ligereza del átomo, su remolino es el de las almas sumisas a la universal gravitación solar. La flauta o trompeta de la resurrección les ha arrancado de sus tumbas: el «viaje» místico del derviche irá, según los sufies, del oriente del ser al occidente del no ser, del occidente del no ser, al oriente de Dios. Vórtice, inmersión, sumidero, la danza aniquila la existencia ilusoria, alegoriza las etapas del ascenso a la desposesión (Goytisolo, 1990: 43).

En el modelo de poema hermenéutico que llamamos infinivertido podemos adivinar la dirección, el aliento, signos implicados en dos componentes fundamentales de la estética de la disolución: el infinito abierto o potencial en dirección al Otro y a lo otro y la progresión de la sombra que se da como trasposición de la emergencia de la forma, el vacío y lo vertido, es decir, la materia liberada por sus restos, sombras, vestigios, ecos, murmullos, etc.

\section{LA INTERIORIDAD Y LA SUSPENSIÓN DEL VER}

La estética de la disolución remite a un estado contemplativo, la primeridad de la simplicidad ${ }^{17}$, según Peirce:

[la Primeridad] es lo primero, presente, inmediato, fresco, nuevo, inicial, original, espontáneo, libre, vívido, consciente y evanescente [Peirce, CP 1.357, 1887].

El poeta se borra del mundo y la palabra poética queda objetivada; no podemos ver al autor. La palabra poética es una palabra indirecta, distanciada: «representa la alteridad constitutiva de la conciencia y de la autoconciencia, es decir, la dialogía interna de la palabra» ${ }^{18}$.

${ }^{17}$ Dinda L. Gorlée explica el carácter directo de la primeridad: «De las tres maneras de percibir hechos, la primeridad es quizás la más difícil de entender, a pesar de representar lo que Peirce llama la prístina simplicidad (CP:8.329). La primeridad significa las ideas de sentimiento espontáneo, no analizado, instantáneo e inmediato» (1992: 17-18).

${ }^{18}$ Alteridad y dialogía que, en cambio, se dejan de lado cuando, como señala A. Ponzio, «la palabra se dirige a un objetivo externo y no a la representación de sí misma, precisamente como "palabra otra". En la literatura no encontramos nunca palabras puras [...] que ponen de manifiesto una sola voz» (1998: 52). 
De la estética de la disolución proceden propiedades espirituales como la pasividad, la pobreza, la desnudez, el desasimiento, que se traducen en el progresivo ensombrecimiento del poema que suena con un ritmo que crece hacia adentro, hacia abajo y hacia atrás, es decir, infinivertido.

Hay una propiedad espiritual en la que los movimientos de la disolución nos remiten a un girar hacia el centro del abismo. Esta experiencia abisal se traduce en una metafísica que teje la organización sintáctica y semántica en los poemas de J. Á. Valente. El carácter espiritual del poema infinivertido estaría muy relacionado con el concepto hindú de akasa, que significa «cero», «cavidad» y «espacio»; el lugar de este espacio está dentro de nosotros: «el aspecto intrínseco de expansión es la ígnea energía celestial en el vacío del hombre interior» (Coomaraswamy, 2001: 261). En consonancia, con esta idea descubrimos que el poema siempre se está infinivirtiendo, es devenir reciproco entre expansión cósmica y cavidad verbal.

En la estética de la disolución, la visión instantánea del vacío está relacionada con la suspensión del ver. Entre la ceguera de la materia y la mirada interior fluye la transparencia, realización de la reciprocidad de apropiación, como observa Valéry:

El universo se encuentra construido sobre un plano cuya simetría profunda está, de alguna manera, presente en la estructura íntima de nuestra mente. El instinto poético debe conducirnos ciegamente a la verdad (1993: 101).

La relación entre la ceguera, la estética de la disolución, la creación y la abstracción la podemos reconocer en un famoso autorretrato de Rembrandt, en el que se pinta con las cuencas vacías ${ }^{19}$, haciendo referencia a su deseo de pintar sin ojos. También encontramos un célebre pasaje de Joyce que trata sobre la importancia de esta experiencia:

Límite de lo diáfano en. ¿Por qué en? Diáfano, adiáfano. Si se pueden meter los cinco dedos a través suyo, es una verja; si no, una puerta.

Cierra los ojos y ve.

Stephen cerró los ojos para oír sus botas aplastando crujientes fucos y conchas. Caminas a través de ello, sea como sea. Yo, una zancada a cada vez. Un cortísimo espacio de tiempo a través de cortísimos espacios de tiempo (1979: 116).

${ }^{19}$ Aix-en-Provence, Musée Granet. 
Esta lectura infinivertida del mundo se repite en muchos poemas de Valente:

...Escribo sobre las humeantes ruinas de lo que

[creímos,

con palabras secretas,

sobre una visión ciega, pero cierta,

a la que casi no han nacido nuestros ojos.

Escribo desde la noche,

desde la infinita progresión de la sombra,

\section{MATERIA Y MEMORIA INFINIVERTIDA}

En la estética de la disolución de la poesía de J. Á. Valente, el limo y la luz son gamas de un continuo. Relacionada con la anterior virtud, se encuentra la interioridad de la palabra, que, al ser vertida en su materia, alcanza el mismo descondicionamiento y libertad de la materia en general.

Las propiedades matéricas y plásticas del modelo infinivertido corresponden a la realidad de la materia de la letra, realidad aglutinante, eruptiva, tumultuosa. Realidad de la materia que corresponde a su textura y urdimbre, por la que lo infinivertido podría verse como fuego vertido en el poema, es decir, el poema como tejido en el fuego, «(Fénix)»:

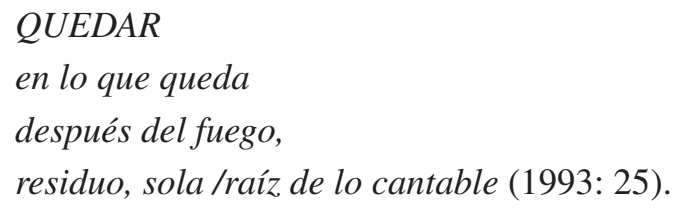

En lo infinivertido de las formas reconocemos el tiempo geológico del poema; palabras, como guijarros arrojados por el mar, llevan inscritas un tiempo infinito que corresponde a la memoria milenaria de la materia.

La formación del poema se va generando en la disolución de las formas, en cuanto las reacciones y los choques de las palabras transfiguran su materia, la adelgazan y transparentan hasta transformarla en energía de radiación, infinivertida. 
La musicalidad de la materia infinivertida, podemos relacionarla con la fuga y, la inversión de su fluir, la estrechez del sí y el no, lo indecidible ${ }^{20}$, con la forma de Stretto de los poemas. El Stretto pensado como la parte de una fuga en la que tan sólo se encuentran fragmentos del tema y se da un dialogo apremiante, con lo que el lenguaje se abre a sus posibilidades trascendentales:

\title{
Pues cómo de otro modo
}

iba a saber si estoy / o si no he vuelto

o cómo si he llegado / o cómo cuándo

si el que ha llegado soy / o el que me espera (1998: 179).

Los fragmentos de lo trascendental oscilan entre lo visible y lo invisible. La fragmentariedad de la estética de la disolución ignora las contradicciones, escapa al habla significativa, se relaciona con el blanco indeterminado a otros textos fragmentarios, está trazada siempre en el límite de lo que expresa, en la línea del sentido que afirma una extraña posibilidad. Infinivertidamente, el sentido, tiene un vaivén en que el fragmento va borrándose, serpenteando fuera de sí mismo hasta ser reconducido, en términos de Blanchot, «al murmullo neutro de la oposición». ${ }^{21}$

Reconocemos cómo los efectos de la ausencia encuentran un discurso en las rupturas, sobreimpresiones, borrones y grietas. Ausencia persistente que escuchamos, también, en los ecos oscuros de los poemas de Paul Celan:

\author{
VIÑADORES excavan \\ el reloj de horas oscuras, \\ de hondura en hondura, \\ tú lees,
}

${ }^{20}$ La infiniversión de lo indecidible progresa entre la estrechez de lo ambiguo en que la palabra poética va acercando o creando su propio pensamiento.

${ }^{21}$ Blanchot aduce que «el habla del fragmento ignora las contradicciones inclusive cuando ella contradice. Dos textos fragmentarios pueden oponerse, se colocan en realidad uno después de otro, el uno sin relación con el otro, el uno relacionado con el otro por ese blanco indeterminado que no los separa ni los junta, que los lleva hasta el límite que designan y que sería su sentido, si no escaparan precisamente allí, en una forma hiperbólica, a toda habla significativa. El hecho de estar planteado siempre de ese modo en el límite, le da al fragmento dos características diferentes: es habla de afirmación, y que no afirma nada más que ese más y ese exceso de una afirmación extraña a la posibilidad y, sin embargo, además, no es en manera alguna categórica, ni está fija en una certeza, ni planteada en una positividad relativa o absoluta, ni mucho menos dice el ser de una manera privilegiada o se dice a partir del ser, sino que más bien va ya borrándose, deslizándose fuera de sí misma, deslizamiento que la reconduce hacia sí...». Vid. http://www.nietzscheana. com.ar/blanchot.htm. 
saca

el Invisible el viento

a la estacada;

tú lees,

los Abiertos llevan

la piedra detrás del ojo,

ella te reconoce (1999: 452).

En el eterno abismo de la viña o mina, el diario geológico de la memoria se mantiene haciarriba y haciabajo; los hilos terrosos del viento trepan en la letra infinivertidamente.

Al reflexionar Valente sobre su experiencia poética, nos dice que, la suya, ha sido una inmersión por las capas infinitas de la «palabra materia», en la que ha pasado por tres ciclos o pruebas: «el ciclo del descenso a la memoria personal, el descenso a la memoria colectiva y el descenso a la memoria de la materia, a la memoria del mundo» ${ }^{22}$. Y los compara con los ciclos del proceso místico:

Al igual que en los místicos, como ustedes saben, se habla de vía purgativa, iluminativa y unitiva, pero en el entendimiento de que esas fases no son rigurosamente sucesivas, la palabra poética avanza también simultánea o desigualmente en esos tres grandes frentes de la memoria (2001: 23).

Este último ciclo, el del descenso a la memoria de la materia o memoria cósmica o infiniversión, ya se anticipa en un poema de 1976 que abre Interior con figuras, cuyo título es «Territorio», en que se trata del lugar de la palabra poética, del tránsito de los umbrales, del acceso a lo infinitesimal, al reverso, a la infinita interioridad de la materia:

Ahora entramos en la penetración, en el reverso incisivo

de cuanto infinitamente se divide (2001: 17).

Descenso al fondo infinito del origen, lugar inmemorial de la palabra única, entrada en «un territorio extremo»:

${ }^{22}$ Se trata, según Valente, de un descenso o viaje, que es, «como todos los viajes, un rito de iniciación» (2001: 23). 
[...] en el territorio de la extrema interioridad, en un lugar del no lugar, del no dónde, en un espacio a la vez vacío y generador, concavidad, matriz, materia mater, materia memoria, material memoria, origen (2001: 17).

Estética de la disolución como descenso a la memoria de la materia, a la interioridad de la palabra, a la nada como flujo generador del mundo, a la meditación de la pura germinación, a la raíz de las formas de lo informe que procede del adentramiento en la materia, a su infinitud como metáfora del espíritu $^{23}$, al fondo del adentro de la palabra, al vacío como origen y como función; al adonde del nunca cuando vibra la nada y somos engendrados en la raíz del aire.

La materia posee un carácter potencial que nos permite comprender el movimiento de formación del poema. Lo potencial, que es otro rasgo de la estética de la disolución, está vinculado al concepto de dýnamis, potencia de Aristóteles ${ }^{24}$, porque es uno de los supuestos radicales que podemos hacer sobre las cosas en cuanto intentamos verlas en el lenguaje y, además, porque su mezcla de ser y no-ser resulta importante en el proceso de la creación ${ }^{25}$ y en la dinámica de los límites y lo infinito.

En el devenir, en el llegar a ser, Aristóteles presenta dos «principios» que actúan en el cambio: la materia que protagoniza el movimiento ${ }^{26}$ como sujeto potencial e indeterminado con respecto al eidos y, éste, el eidos (o morphé), que corresponde al momento determinante y actualizante.

${ }^{23}$ Aquí debemos conciliar la filología con la estética y citar las reflexiones que hace Valente sobre Tapies, por tratarse de dos creadores que siguen caminos análogos en la búsqueda del absoluto: «Entrada radical en la materia, contemplación de la materia, la obra de Tapies niega por su naturaleza misma toda ruptura entre espíritu y materia. Esa materia que antes de manifestarse ha sido interiorizada, ha sido unificada y percibida en su espontáneo movimiento, se aproximaría mucho a lo que Novalis llama en el Himno 1 «lo más interior del alma de la vida» (Lebens innerste Seele). Este arte busca de nuevo la materia en su último ser y como radix ipsius: El cumplimiento de la obra (como sucedía en el saber antiguo de la alquimia) es tanto un proceso interior como el ejercicio visible de un arte. Porque el movimiento hacia el centro de la materia es también un movimiento hacia el centro de la interioridad» (1999b: 43-44).

${ }^{24}$ La dynamis, según Aristóteles, compone el movimiento: «distinguimos en cada género lo actual y lo potencial, el movimiento es la actualidad de lo potencial en cuanto a tal» (1995: 178).

${ }^{25}$ Aristóteles describe como hay algo que mueve y es inmóvil: «en ocasiones una misma cosa puede estar en potencia y en acto — no a la vez y bajo el mismo respecto, sino como lo caliente en potencia y frío en acto:-, se sigue que habrá muchas cosas que actúen y se modifiquen entre sí, pues cada una de ellas será a la vez activa y pasiva. Luego el moviente es también naturalmente movible, ya que cuando mueva será movido. Hay algunos que piensan que todo lo que mueve es movido, pero no es así» (1995: 179).

${ }^{26}$ En el capítulo 1. del Libro III de la Física, Aristóteles redefine el movimiento haciendo precisiones sobre el «en tanto que» y la actualidad transitiva (1995: 176-186). 
El cambio está en la transición de la materia. Lo que cambia en las cosas es lo que éstas tienen de potencial, lo cual «no es un dato empírico sino un reducto analítico» ${ }^{27}$; es la materia como suposición conceptual.

La materia es un no-ser, en el sentido de «privación» ${ }^{28}$, stéresis, el «de dónde».

La materia es el sustrato del cambio del que es educido el principio formal, el eidos; por tanto la forma no es algo que se agregue a la materia, sino que, como sucede en la poesía de Valente, es algo segregado por ésta; la forma sólo existe sonora y respirada como en el hondo cántaro de tierra:

El cántaro que tiene la suprema

realidad de la forma,

creado de la tierra

para que el ojo pueda

contemplar la frescura.

El cántaro que existe conteniendo,

hueco de contener se quebraría

inánime. Su forma

existe sólo así,

sonora y respirada.

El hondo cántaro

de clara curvatura,

bella y servil:

el cántaro y el canto (1998: 43).

$\mathrm{Al}$ ir al adentro de las palabras, vemos cómo las letras ejecutan la oscuridad de la materia; la tinta está sola en la profundidad del tiempo, es tierra o arena hasta que el magnetismo del sonido hace aparecer la $c$, la $a$, la $t$, la $r$,

${ }^{27}$ Aristóteles define el cambio como la actualidad transitiva de lo potencial en cuanto tal: «la actualidad de lo alterable en tanto que alterable es la alteración, la de lo susceptible de aumento y la de su contrario, lo susceptible de disminución — no hay nombre común para ambos-, es el aumento y la disminución; la de lo generable y lo destructible es la gene ración y la destrucción; la de lo desplazable es el desplazamiento» (1995: 178).

${ }^{28}$ Para Aristóteles lo que cambia siempre cambia o sustancialmente o cuantitativamente o cualitativamente o localmente y, estas categorías están presentes de dos maneras: «con respecto a un «esto», en su forma o su privación; con respecto a la cualidad, en 1 o blanco o lo negro; con respecto a la cantidad, en lo completo o lo incompleto; y de la misma manera con respecto al desplazamiento en el arriba o el abajo, lo pesado o lo ligero. Por consiguiente, las especies del movimiento y del cambio son tantas como las del ser» (1995: 178). 
etc. La materia es también en Aristóteles una analogía del infinito en cuanto potencialidad $^{29}$. Sustenta el filósofo, además, que el infinito es incognoscible $^{30}$ porque como la materia en su divisibilidad infinita no tiene formas actuales, es inagotable y, no es un todo, ni es completo; porque:

[...] aquello fuera de lo cual hay algo ausente, sea lo que sea, no es un todo. «Todo» $y$ «completo» o son enteramente idénticos o son muy próximos en su naturaleza, Nada es completo si no tiene fin, y el fin es un límite (1995: 207).

Esta falta de completitud es evidente en la infinitud del poema que siempre está indicando fuera de él algo ausente. La infinitud de la poesía en general, puede coincidir también con la división establecida por Aristóteles: «todo lo que es infinito puede serlo o por adición o por división o por ambos» (1995: 193).

La imposibilidad de recorrer la voz, según Aristóteles, es un caso de lo infinito $^{31}$. Lo primero que se manifiesta en lo continuo es el infinito. Significa causa como materia: «es evidente que su ser es privación, y que el sujeto en virtud de lo cual existe es algo continuo y sensible» (1995: 211).

El continuo parece subyacer en la formación del poema, el cual, por la división de la materia nos permite acercarnos a lo infinito, disolver el abismo entre el grano, el pájaro y el sol y, así, deslindar la transparencia.

Otro rasgo de la estética de la disolución es la retracción, en tanto proceso rítmico que «suspende» el mundo inmediato para adentrarse en paisajes abstractos del preaparecer, por fugas que suelen retornar con una nueva luz; según Domínguez Rey, comporta «una postura fenomenológica de revisión crítica y, a la par, de fundamento rítmico». Sus procesos ausentan el mundo inmediato y ponen límites entre «la experiencia originaria de los sentidos y el sentir las cosas» ${ }^{32}$.

${ }^{29}$ Aristóteles estipula el modo de realidad del infinito en potencia y por reducción. Y sólo «existe actualmente en el sentido en que decimos que el día o la competición existen; y existe potencialmente, como la materia; pero no existe por sí mismo, como existe lo finito» (1995: 205).

${ }^{30}$ No se puede conocer en el sentido de que es un proceso incesante, inagotable.

${ }^{31}$ Así pues, testifica Aristóteles: «tenemos que determinar, ante todo, los distintos sentidos del término "infinito" 1) En un caso llamamos infinito a lo que es imposible recorrer, porque por su propia naturaleza no puede ser recorrido (como una voz, que es invisible); 2) en otros, lo que se puede recorrer, pero sin llegar a un término, o a) lo que difícilmente puede ser recorrido, o b) lo que naturalmente admite ser recorrido, pero no puede ser recorrido o no tiene límite» (1995: 193).

${ }^{32}$ Es el efecto de la epojé, argumenta Domínguez Rey, «suspensión racional del mundo inmediato para educir en él una razón explicativa que lo fundamente. De su proceso suele considerarse sólo el camino ascendente, la abstracción, y no el de vuelta, la Rückkehre heideggeriana, que nos devuelve al mundo antes acotado, pero con una nueva luz iluminadora» (2002: 175). 
La retracción implica, pues, una «actitud de repliegue y retroceso», pasividad que se abre a una complejidad temporal. La acción se retrotrae hacia un punto originario, como «si tiráramos hacia atrás, hacia antes, lo que ya es después, cuanto en su día fue futuro» ${ }^{33}$.

La estructura infinivertida del poema detecta un trans-mundo o un mundo anterior al mundo. Una invasión de sombras proyectada sobre el lenguaje (Díaz Gamboa, 2009: 65).

La infiniversión constituye, así, una herramienta clave para entender la estética de la disolución porque abarca la indeterminación, el enigma del límite, es decir, la disolución de la palabra en el silencio o en la luz, la trascendencia ${ }^{34}$, los rastros subterráneos del aire, el «antecomienzo» y el autoborrarse, la absoluta libertad interior.

La infiniversión indica que existe un camino abierto por el texto que conduce en estrechez la palabra, el silencio, el limo y luz. Una progresión del lector y del texto que se cumple mediante la rememoración.

\section{REFERENCIAS BIBLIOGRÁFICAS}

ARISTÓTELES (1995). Física. Madrid: Gredos.

BAJTíN, M. (1981). «Dagli appunti del 1970-71». C. Strada Janovic (trad.). Intersezioni 1, 125-139.

BENLABBAH, F. (2008). «Huellas sufíes en la poética de José Ángel Valente». En Valente: el fulgor y las tinieblas, C. Rodríguez Fer (ed.), 131137. Lugo: Axac.

BLANCHOT, M. (1990). La escritura del desastre. Caracas: Monte Ávila.

- (2006). «Nietzsche y la escritura fragmentaria». http://www.nietzscheana. com.ar/blanchot.htm.

CELAN, P. (1999). Obras completas. Madrid: Editorial Trotta.

${ }^{33}$ No se trata, sin embargo, sostiene Domínguez Rey, «de ir hacia ayer o de reavivar el pasado. Tampoco de corregir el decurso del tiempo para situarlo en un cauce más idóneo, como si fuéramos dueños de un saber o acierto más ejemplar» (2002: 175).

${ }^{34}$ Domínguez Rey explica que el lenguaje es más que una máquina porque, «Su estructura interna abre un resquicio que lo posibilita como momento de la transpiración universal de las lenguas y el mundo, pues su léxico no abarca la totalidad de relaciones reales y ha de figurarlas con saltos o frases que las evoquen, designen o simplemente figuren con la imaginación. El léxico ya contiene lo que pretende explicar, porque lo traslapa y trasciende» (2007: 7-8). 
CHENG, F. (1993). Vacío y plenitud. Madrid: Ediciones Siruela.

CHILliDA, E. (1998). Chillida, 1948-1998. Museo Nacional Centro de Arte Reina Sofía, 15 de diciembre de 1998-15 de marzo de 1999. Madrid: Museo Nacional Centro de Arte Reina Sofía.

COOMARASWAMY, A. (2001). El Vedanta y la tradición occidental y otros ensayos. Madrid: Siruela.

DÍAZ GAMBOA, S. (2008). La experiencia de los límites en la obra de José Ángel Valente y sus «implicaciones» lógico-matemáticas, 2 v. [tesis doctoral]. Madrid: Universidad Nacional de Educación a Distancia, Facultad de Filología.

- (2009). «La formación de conceptos poético-matemáticos en la obra de José Ángel Valente». SERTA. Revista Iberorrománica. Poesía y Pensamiento Poético 10, 56-80.

DOMÍNGUEZ REY, A. (2002). Limos del verbo (José Ángel Valente). Madrid: Verbum / Universidad Nacional de Educación a Distancia.

- (2007). «Límites del lenguaje». SERTA. Revista Iberorrománica. Poesía y Pensamiento Poético 9, 1-19.

- (2008). Palabra respirada: hermenéutica de lectura. Madrid: Universidad Nacional de Educación a Distancia.

GORLÉE, D. (1992). «La semiótica triádica de Peirce y su aplicación a los géneros literarios». Signa. Revista de la Asociación Española de Semiótica 1, 13-51 (también en http://cervantesvirtual.com/hemeroteca/signa).

GOYTISOLO, J. (1990). «Los derviches giróvagos». En Aproximación a Gaudi en Capadocia. Madrid: Mondadori.

HERRIGEL, E. (1999). El camino del Zen. Barcelona: Paidós.

HOFSTADTER, D. (1987). Gödel, Escher, Bach. Un eterno y grácil bucle. Barcelona: Tusquets.

JANKELEVITCH, W. (1986). La ironía. Madrid: Taurus.

JIMÉNEZ J. (1998). La palabra emplazada. Meditación y contemplación de Herbert a Valente. Córdoba: Universidad de Córdoba.

JOYCE, J. (1979). Ulises, vol.1. Barcelona: Editorial Lumen.

LUCRECIO C. T. (2003). La naturaleza. Madrid: Gredos. 
PEIRCE, Ch. S. (1931-35). Collected Papers of Charles Sanders Peirce, vols. 1-6, C. Hartshorne and P. Weiss (eds.). Cambridge: Harvard University Press (las referencias a Peirce serán consignadas como CP)

- (1958). Collected Papers of Charles Sanders Peirce, A. W. Burks (ed.), vols. 7-8. Cambridge: Harvard University Press (las referencias a Peirce serán consignadas como $\mathrm{CP}$ ).

PONZIO, A. (1995). «El silencio y el callar. Entre signos y no signos». En Bajtín y la Literatura, J. Romera Castillo et alii (eds.), 27-42. Madrid: Visor Libros.

- (1998). La Revolución Bajtiniana. El Pensamiento de Bajtín y la Ideología Contemporánea. Madrid: Cátedra.

RYCKMANS, P. (1993). «Poesía y Pintura. Aspectos de la Estética China Clásica». El Paseante \#20-22.

SERRES, M. (1994). El nacimiento de la Física en el texto de Lucrecio. Caudales y turbulencias. Valencia: Pre-Textos.

SUZUKI, D. (2005). El zen y la cultura japonesa. Barcelona: Paidós.

VALENTE, J. Á. (1993). Al Dios del lugar. Barcelona: Tusquets.

- (1996). Cántigas de alén, edición e introdución de Claudio Rodríguez Fer y traducción al castellano del poeta y de César Antonio Molina, con cuatro grabados de Eduardo Chillida. Santiago de Compostela: Consorcio de Santiago.

- (1998). El fulgor. Antología poética (1953-1996), selección y prólogo de Andrés Sánchez Robayna. Barcelona: Galaxia Gutenberg.

- (1999a). Obra poética. 1. Punto cero (1953-1976). Madrid: Alianza.

- (1999b). Obra poética. 2. Material memoria (1977-1992). Madrid: Alianza.

- (2000). Fragmentos de un libro futuro. Barcelona: Galaxia Gutenberg: Círculo de Lectores.

- (2001). La voz de José Ángel Valente. Poesía en la residencia. Madrid: Residencia de Estudiantes.

- (2006). Obras completas I. Poesía y prosa, edición e introducción de Andrés Sánchez Robayna. Barcelona: Galaxia Gutenberg / Círculo de Lectores. 
- (2008). Obras completas II. Ensayos, edición de Andrés Sánchez Robayna e introducción y recopilación de Claudio Rodríguez Fer. Barcelona: Galaxia Gutenberg / Círculo de Lectores.

VALÉRY, P. (1993). Estudios filosóficos. Madrid: Visor.

ZELLINI, P. (1991). Breve historia del infinito. Madrid: Ediciones Siruela.

Recibido el 22 de noviembre de 2010.

Aceptado el 22 de septiembre de 2011. 
